Os anéis da serpente:

a aprendizagem baseada em problemas e as sociedades de controle

\author{
The rings of snake: \\ problem-based learning and the societies of control
}

Rodrigo Siqueira-Batista ${ }^{1}$

Romulo Siqueira-Batista ${ }^{2}$

\footnotetext{
${ }^{1}$ Curso de Graduação em

Medicina, Centro

Universitário Serra dos

Órgãos(UNIFESO) e

Instituto Federal de

Educação, Ciênciae

Tecnologia do Rio de

Janeiro (IFRJ). Av. Alberto

Torres, 111 - Alto.

25964-000 - Teresópolis RJ

anaximandro@hotmail.com

${ }^{2}$ Curso de Graduação em

Ciência da Computação,

Centro Universitário Serra dosÓrgãos.
}

Abstract The imperative need for modifying the Brazilian medical education - aiming at the formation of a professional more capable to answer the population's main health problems - has opened the possibility for the use of new teaching methodologies. In this scenario, the Problem Based Learning (PBL) outstands as the curriculum structuring tool adopted in several institutions, showing as main characteristics the capability of fostering (1) significant learning, (2) the undissociated link between theory and practice, (3) the respect for the student's autonomy, (4) the work in small groups, (5) the permanent education and (6) the formative evaluation. Despite its indisputable leading position, PBL can be understood as a way to exercise power in the context of an emerging modus of social organization: the societies of control.

Key words Problem-based learning, Societies of control, M edical education
Resumo A prementenecessidade de transformar a educação médica brasileira - objetivando formar um profissional mais capaz de dar respostas aos principais problemas desaúde da população - tem aberto perspectivas para a utilização de novas metodologias de ensino-aprendizagem. N este âmbito, vem se destacando a aprendizagem baseada em problemas ( $A B P)$, modalidade de estruturação curricular que tem sido adotada em diferentes instituições de ensino, possuindo, como principais características, a possibilidade defomentar (1) a aprendizagem significativa, (2) a indissociabilidade entre teoria e prática, (3) o respeito à autonomia do estudante, (4) o trabalho em pequeno grupo, (5) a educação permanente e (6) a avaliação formativa. A despeito de sua indiscutível posição de vanguarda, a ABP podeser compreendida como uma forma para o exerć́cio do poder no contexto de um nascente modus de organização social: as sociedades de controle. Discutir esta questão é o escopo do presente artigo. Palavras-chave A prendizagem baseada em problemas, Sociedade de controle, Educação médica 
Introdução

Os debates atuais em torno do binômio saúdeeducação têm ratificado a necessidade de implementar, de forma cogente e duradoura, profundas transformações nos processos de formação profissional em saúde ${ }^{1}$.

É precisamenteneste contexto queseinscreveo atual movimento de discussão sobre a mudança no ensino médico brasileiro, o qual vem sendo fomentado há mais detrinta anos, especialmenteapós o estabelecimento, pela Associação Brasileira de Educação M édica, dos fóruns de discussão e reflexão sobre as mudanças necessárias nos currículos das faculdades de medicina². Algumas iniciativas têm sido construídas neste sentido, cabendo destaque a adoção, por parte de al gumas escolas brasileiras, da aprendizagem baseada em problemas $(A B P$, sigla em português correspondente a $P B L=$ problem-based learning), modalidade de dinâmica curricular organizada para o desenvolvimento da habilidade de resolução de problemas, centrada no estudante - sujeito crucial no processo ensino-aprendizagem - , o qual se torna apto a construir, de forma madura, o próprio conhecimento, perspectiva inscrita no âmago da práxis de aprender a aprender ${ }^{3-5}$.

A despeito de alguns avanços obtidos em relação à pergunta como mudar o ensino no curso de graduação em medicina no Brasil? - ea ABP, nesses casos, é uma das possíveis respostas - , tem se tornado, cada vez mais urgente, a reflexão sobre aquela que pode ser considerada a indagação capital, e anterior à primeira, qual seja, afinal, por quemudar a formação médica no país? Um dos pontos-chave para se discutir esta interrogação éa premência de tornar o aparelho formador mais eficaz para se cultivar um egresso capaz de lidar com os problemas da sociedade brasileira hodierna, cujos pontos de maior relevância - à semelhança do observado em outras sociedades democráticas contemporâneas, laicas, plurais e complexas - seriam ${ }^{6-11}$ :

(1) a celeridade das transformações sociais, em um contexto no qual a produção de conhecimento é extremamenteveloz, tornando ainda mais provisórias as "verdades" construídas no domínio da ciênciabiomédica;

(2) a necessidade de reorganizar o saber/fazer da saúde, levando em consideração a integralidade, a interdisciplinaridade e a recuperação da dimensão ética cuidadora/compassiva, bem como a necessidade de otimização dos gastos em saúde, face às infrenes produção de conhecimento e incorporação tecnológica em saúde;

(3) a perspectiva vigente, quase "marca" deste tempo, de colocar em "xeque" os valores até então considerados intocáveis, o que impõe a reflexão sobre a inserção do profissional de saúde neste novo contexto;

(4) a inequívoca influência dos meios de comunicação na construção/formatação do homem/ profissional nestes primórdios do século XXI, marcada por um genuíno "bombardeio" de imagens, as quais "embotam" as possibilidades de re flexão sobre a vida, a inserção no mundo e a própria práxis; e

(5) a configuração de uma nova modalidade de organização do espaço-tempo social, as sociedades de controle, as quais operam nos meandros de um sistema aberto - em contraposição às (em ultrapassagem, senão completamente ultrapassadas) sociedades disciplinares, constituídas em torno de estratégias de confinamento.

Pode-seconceber que, em certa medida, os quatro primeiros pontos estão intimamente ligados à questão das sociedades de control $\mathrm{e}^{11}$, provavelmente um dos pontos cruciais - eainda pouco explorados - do mundo ocidental contemporâneo.

Em relação à educação - médica, no caso cabe-se perguntar até que ponto as mais recentes transformações na formação dos profissionais especialmente a $A B P$ - não seriam, em última análise, modos de estabelecer e perpetuar as relações de poder no âmbito das sociedades de controle, em um obscuro processo de implantação do domínio, sem face e sem cor. Deste modo, discutir as [possíveis] relações entre a aprendizagem baseada em problemas e as sociedades de controle é 0 escopo do presente artigo.

\section{Aprendizagem baseada em problemas}

A ABP foi primeiramente instituída na Faculdade de M edicina da U niversidade de M CM aster (Canadá), na década de sessenta. No Brasil, as instituições precursoras na implantação desta modalidade de estrutura curricular foram a Faculdade de M edicina de M arília, em 1997, eo Curso de M edicina da Universidade Estadual de Londrina, em 1998. No Estado do Rio de Janeiro, o curso de graduação em M edicina da Fundação Educacional Serra dos Órgãos (FESO) - atual Centro Universitário Serra dos Órgãos (UNIFESO) - foi pioneiro em um contexto de adoção curricular de metodologias ativas de ensino-aprendizagem - , em 2005 12-14.

A necessidade de romper com a postura de mera transmissão de informações, na qual os estudantes assumem o papel de receptáculos passivos, preocupados apenas em memorizar conteú- 
dos e recuperá-los quando solicitados - habitualmente, por ocasião de uma prova - , é um dos principais pontos de partida que explicam a ascensão da ABP no ensino médico atual ${ }^{4}$. De fato, um dos aspectos cruciais da ABP éo processo educativo centrado no estudante ( $Q$ uadro 1 ), permitindo que este seja capaz de se tornar maduro, adquirindo graus crescentes de autonomia.

Na ABP, parte-se de problemas ou situações que objetivam gerar dúvidas, desequilíbrios ou perturbações intelectuais, com forte motivação prática e estímulo cognitivo para evocar as reflexões necessárias à busca de adequadas escolhas e soluções criativas, podendo-se estabelecer uma aproximação à proposta educativa formulada por John Dewey ${ }^{15-17}$. Ademais, a ABP se inscreve em uma perspectiva construtivista - relacionada, especialmente, aos referenciais da teoria piagetiana da equilibração e desequilibração $\operatorname{cognitiva}^{18}-$, a qual considera que o conhecimento deve ser produzido a partir da interseção entre sujeito e mundo, como amplamente problematizado por teóricos como Leon Vigotsky e Paulo Freire ${ }^{19-21}$.

Com base nessas considerações, podem ser pontuados como principais aspectos da ABP (1) a aprendizagem significativa, (2) a indissociabilidade entre teoria e prática, (3) o respeito à autonomia do estudante, (4) o trabalho em pequeno grupo, (5) a educação permanente e (6) a avaliação formativa.

. A prendizagem significativa. Esta se estrutura, complexamente, em um movimento de continuidade/ruptura. 0 processo de continuidadeéaquele no qual o estudanteécapaz de relacionar o conteúdo apreendido aos conhecimentos prévios, ou seja, o conteúdo novo deve apoiar-seem estruturas cog- nitivas já existentes, organizadas como subsunçores; o processo de ruptura, por outro lado, instaura-se a partir do surgimento de novos desafios, os quais deverão ser trabal hados pela análise crítica, levando 0 aprendiz a ultrapassar as suas vivências (conceitos prévios, sínteses anteriores eoutros), tensão que acaba por possibilitar a ampliação de suas possibilidades de conhecimento ${ }^{22,23}$.

- Indissociabilidade entre teoria e prática. A profunda integração teoria-prática estabelece-sena medida em que os problemas são elaborados a partir de situações cotidianas - as quais colocam a realidade diante do estudante - , permitindo, assim, a possibilidade de se desenvolverem múltiplas habilidades educacionais, as quais poderão ser empregadas para equacionar e resolver problemas concretos do mundo da vida 4 .

- Respeito à autonomia do estudante. Pressupõequeo estudantedetém, defato, a capacidadede se auto-legislar (auto-governar, auto-gerir) - 0 termo autonomia origina-se do grego $\alpha \eta \tau o v o \mu i ́ \alpha$, de $\alpha \eta \tau o ́ s=$ próprio, e vónos = lei) - , o que é entendido em termos da autodeterminação da pessoa, em princípio a mais qualificada para avaliar e decidir o rumo de sua vida, desde que possa ser considerada cognitiva e moralmente competente ${ }^{24}$. $\mathrm{NaABP}$, estimula-se que o aprendiz se torne capaz de assumir a responsabilidade por sua formação, o que representa uma importante preparação para a vida profissional, uma vez que este deverá se tornar hábil em julgar a importância relativa - e ponderada - dos diferentes saberes para o exercício de suas atividades laborais ${ }^{20,25}$.

- Trabalho em pequeno grupo. É desenvolvido no âmago do grupo tutorial, constituído por oito a dez estudantes e mais um tutor - , importante

Quadro 1. Distinções entre a aprendizagem centrada no estudante e no professor.

\begin{tabular}{|l|l|}
\hline Aprendizagem centrada no estudante & Aprendizagem centrada no docente \\
\hline $\begin{array}{l}\text {. Autônoma, ou seja, motivada por fatores internos, } \\
\text { tais como: }\end{array}$ & . H eterônoma, ou seja, motivada por fatores externos, \\
- auto-estima & - notas e diplomas \\
- curiosidade e responsabilidade & - prêmios e títulos \\
- espírito e cooperação & - medo de fracassar \\
. Promove o desenvolvimento de um estudante ativo & . Impõe a permanência de um estudante passivo \\
. O aprendizado é, na maior parte das ocasiões, algo & . O aprendizado é, muitas vezes, motivo de \\
prazeroso & sofrimento \\
. Estimula a imaginação & . Estimula a dependência \\
. Docente é um facilitador, um guia para o & . Docente é o centro do universo, fonte inconteste \\
crescimento do estudante & do saber \\
\hline
\end{tabular}

Fonte: Baseado em Venturelli J $]^{4}$. 
para o desenvolvimento das habilidades de coope ração, aspecto fundamental para o trabalho em equipe (Figura 1). 0 trabal ho tutorial consta dos seguintes passos: (a) leitura do problema no grupo eesclarecimento dostermos desconhecidos, (b) identificação dos problemas propostos pelo enunciado, (c) levantamento de hipóteses explicativas para os problemas apontados, com base nos conhecimentos preexistentes dos estudantes, (d) resumo das hipóteses, (e) definição dos objetivos de estudo necessários à resolução do problema, (f) estudo individual e $(\mathrm{g})$ retorno ao grupo para re discussão fundamentada nos conhecimentos adquiridos ${ }^{26}$. Vale ressaltar que 0 grupo de tutoria consiste em um fórum de discussão - um genuíno laboratório - no qual se possibilita uma aprendizagem sobre a interação humana, constituindo- se em uma oportunidade para aprender a ouvir, receber e assimilar críticas $^{27}$.

- Educação permanente. A educação permanente (EP) é um dos pontos fundamentais da $A B P$. Tal necessidade é compreendida ao se comparar, em termos cronológicos, o tempo de formação (pré e per universitária) eo tempo de atuação profissional (Figura 2). A idéia, consistente, édequeo período de graduação éincapaz defornecer todo o conhecimento necessário ao sujeito em formação. Deste modo, torna-se mais produtivo aprender a resolver os problemas que a prática profissional impõe - aspecto quesesolidariza ao conceito deaprender a aprender - , capacitando-se para a resolução dos mais diferentes problemas, do que adquirir uma série de conteúdos, os quais poderão estar obsoletos poucos anos após a conclusão da graduação ${ }^{4,28}$.

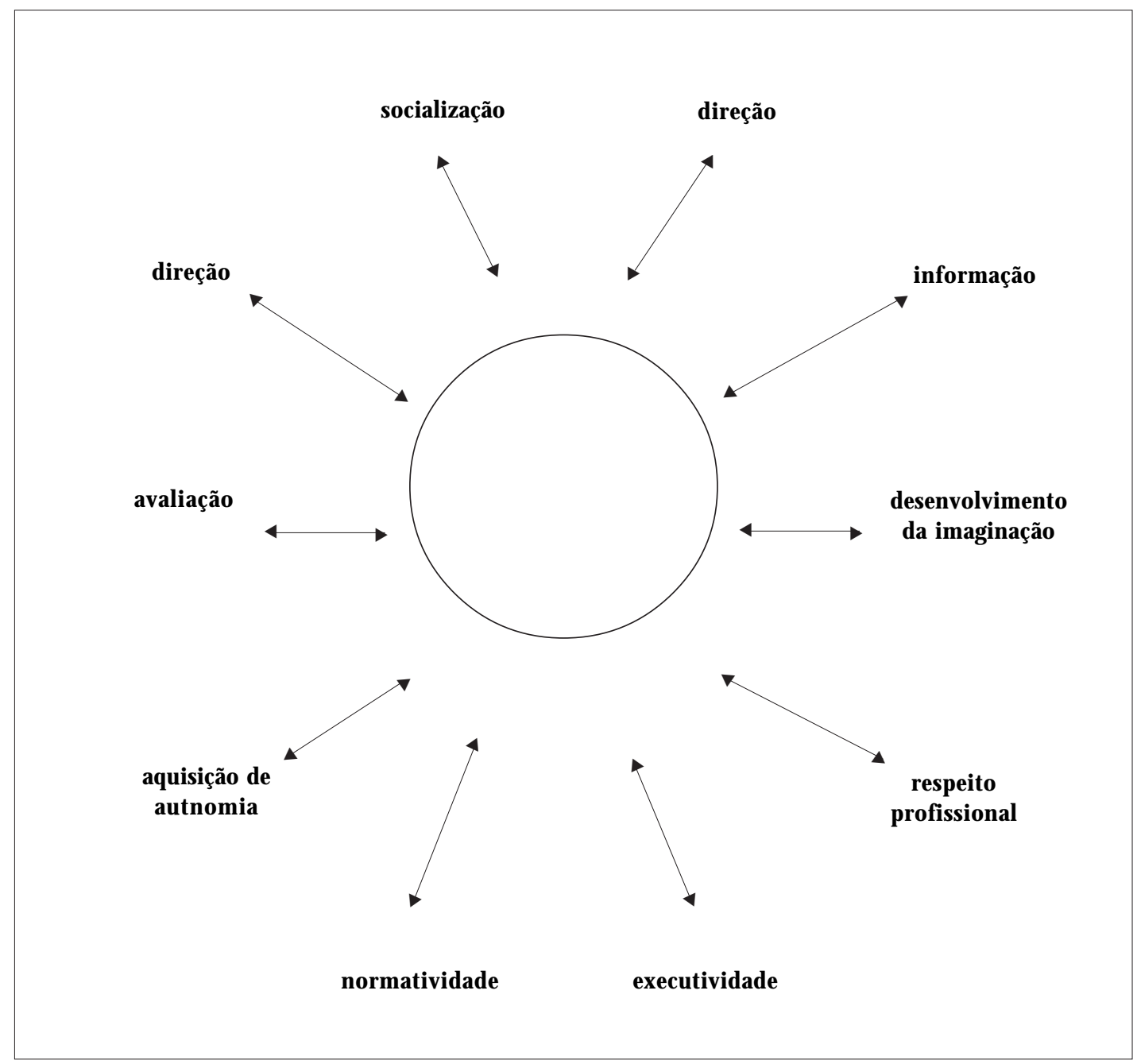

Figura 1. Aspectos do trabalho em grupo.

Fonte: Baseado em Venturelli J ${ }^{4}$. 


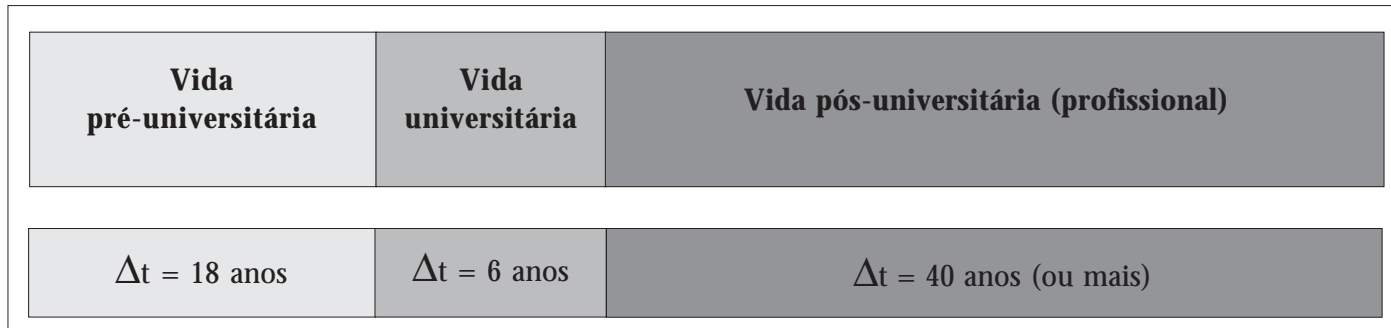

Evolução (e ampliação) do conhecimento científico

Figura 2. Tempo, educação e trabalho: o caso do ensino médico. Conforme (1) Venturelli J ${ }^{4}$ e Siqueira-Batista R ${ }^{28}$.

$M$ ais recentemente, tem-se, inclusive, trabalhado com a perspectiva de incluir todos os atores no processo de EP, e não apenas os profissionais de saúde ${ }^{29}$. Todas as nossas ações envolvem sempre a dimensão de capacitação eeducação permanentedos estudantes, dos profissionais e dos pacientes e seus familiares. Pacientes e familiares são muitas vezes 'esquecidos' neste processo de capacitação e de educação continuada, o que pode provocar uma série de distorções. Consideramos fundamental sua inclusão, pois, só assim poderemos caminhar para uma mudança consistente na relação terapêutica, distanciada de assistencialismo e paternalismo.

$\mathrm{Na}$ atenção à educação permanente, sempre procuramos abarcar os diversos níveis institucionais (alunos, médicos, profissionais desaúdeem geral, profissionais administrativos, pacientes e familiares) ${ }^{29}$.

Em linhas gerais, a idéia é (1) estabelecer uma rede de interações entre os diferentes partícipes do processo - coordenando e controlando, muitas vezes, suas respectivas intervenções nos processos saúde-doença, próprios e de outrem - e(2) capacitar o profissional de saúde para exercer atividades em concordância com o avanço do conhecimento científico 4 .

. Avaliação formativa. É baseada na apreciação de todos os aspectos do processo educacional, incluindo o programa, os docentes, os gerentes, os estudantes, os resultados, os materiais eas mudanças. Torna-se importante destacar que os atores envolvidos devem ter sempre em conta a auto-avaliação, baseada na capacidade crítica, em uma perspectiva de contínua reflexão sobre a prática ${ }^{4} \mathrm{Na}$ ABP, a avaliação dos estudantes passa pelo estabelecimento de uma estreita relação entre este e os docentes, os quais deverão ser também avaliados. Os principais aspectos da avaliação formativa no trabalho em pequeno grupo são (1) a auto-avaliação do estudante, (2) a avaliação recíproca interpares (todos os educandos avaliam o desempenho detodos os educandos), (3) avaliação do estudante pelo tutor e (4) a auto-avaliação do tutor ${ }^{26}$. Estas ações - associadas à avaliação das habilidades e atitudes do aprendiz - permitem controlar o processo de formação do estudante, garantindo que sejam contemplados os objetivos educacionais propostos e/ou adquiridas as competências necessárias ao desenvolvimento do seu mister.

Como pôde ser observado nestes breves comentários, um dos aspectos que mais chamam a atenção diz respeito à capacidade que tem a $A B P$ de permitir a formação de um estudante apto a construir seu próprio conhecimento e de trabalhar em grupo de modo articulado e fecundo. Ademais, a perspectiva de não-completude da formação (expressa no conceito/práxis de educação permanente) e a estruturação do processo de avaliação formativa e contínua - os quais esmaecem, de fato, as diferenças entre as vidas universitária e profissional (Figura 2) - parecem fazer parte de um sistema aberto de organização do processo ensinoaprendizagem, no qual seabremão, definitivamente, da noção de terminalidade da formação.

0 debate teórico sobre estes dois últimos pontos - educação permanente e avaliação formativa - permite que sejam colocadas em questão as relações entre a ABP e as sociedades de controle, tal qual formulada pelos filósofos Michel Foucault e Gilles D eleuze, mote das discussões entabuladas a seguir. 
Continuidades e rupturas: sociedade disciplinar $\rightarrow$ sociedade de controle

As sociedades de controle consistem em uma modalidade de organização social típica do capitalismo tardio, tendo sido uma resposta à crise das sociedades disciplinares: N esses últimos anos, a sociedademudou eos indivíduostambém; elessão cada vez mais diversos, diferentes e independentes. Há cada vez mais categorias de pessoas que não estão submetidasà di sciplina, detal forma que somos obrigados a pensar o desenvolvimento de uma sociedade sem disciplina ${ }^{30}$.

A sociedade disciplinar, sucessora das sociedades de soberania - Deleuze situa em N apoleão a grande conversão de uma a outra ${ }^{11}$ - é marcada pela organização em termos de espaços de confinamento - cujo projeto ideal pode ser reconhecido na fábrica: concentrar, distribuir no espaço, ordenar no tempo, compor no espaço-tempo uma força produtiva cujo efeito deve ser superior à soma das forças elementares - , nos quais a disciplina é exercida de forma institucionalizada, em espaços fechados, havendo necessidade de se passar de um para o outro ao longo da vida: 0 indivíduo não cessa de passar de um espaço fechado a outro, cada um com suas leis: primeiro a família, depois a escola ( "vocênão está maisna sua família"), depois a caserna ("vocênão está mais na escola"), depois a fábrica, devez em quando o hospital, eventualmentea prisão, que é o meio de confinamento por excelência ${ }^{11}$.

Os confinamentos são moldes, nos quais se opera o poder em diferentes âmbitos. D efato, Foucault reconhece que o poder sobre a vida nas sociedades modernas se estabeleceem dois pólos - anátomo-política do corpo e biopolítica das populações - , os quais são interconectados por múltiplas redes de relações ${ }^{31}$. A anátomo-política do corpo diz respeito ao desvendamento e produção de discursos e práticas sobre o corpo humano - abordado como máquina a ser otimizada, disciplinada em sua docilidade e produtividade - ao passo que a biopolítica das populações é dirigida aos elementos biológicos e sociais, tais como reprodução, nascimento e morte. Ambas as dimensões - o indivíduo (anátomo-política do corpo) e a massa (biopolítica das populações) - são dispositivos, compatíveis entre si, da organização disciplinar.

A crise dos confinamentos, agudizada após a Segunda Guerra Mundial, representa a agonia ante a precipitação da nova forma de exercício do poder que se anuncia: o controle. A transição para esta modalidade de ordenação social é antevista segundo a interpretação de Deleuze, por Franz Kafka, em 0 processo32: Esqueci de lhe perguntar que tipo de libertação deseja. Existem três possibilidades: ou seja, a absolvição real, a absolvição aparente e o processo arrastado. Naturalmente o melhor é a absolvição real, só que não tenho a mínima influência sobre este tipo de solução. Na minha opinião, não existe nenhuma pessoa que pudesse ter influência sobre a absolvição real. Provavelmente, aqui decide apenasa inocência do acusado. U ma vez que o senhor é inocente, seria de fato possível que confiasse apenas na sua inocência. M as aí já não precisa de mim nem de qualquer outra ajuda.

As duas formas jurídicas descritas no romance kafkiano, a absolvição aparente e o processo arrastado, são, respectivamente, imagens das sociedades disciplinares (entre dois confinamentos) e das sociedades de controle (em variação contínua) ${ }^{11}$. Como Kafka, Foucault prevê o temível cenário: $\mathrm{H}$ oje, o controleémenos severo emais refinado, sem ser, contudo, menos aterrorizador. Durante todo o percurso de nossa vida, todos nós somos capturados em diversos sistemas autoritários; logo no início na escola, depois em nosso trabalho e até em nosso lazer. Cada indivíduo, considerado separadamente, é normatizado e transformado em um caso controlado por um IBM. Em nossa sociedade, estamos chegando a refinamentos de poder os quaisaqueles que mani pulavam o teatro do terror [nas execuções penais públicas] sequer haviam sonhado ${ }^{30}$.

O cerne da passagem de uma a outra sociedade pode ser compreendido na transformação da fábrica em empresa. Na fábrica - um corpo modelo da sociedade disciplinar marcado pelo adestramento - estabelecia-se um equilíbrio da massa (de trabalhadores), cujo sentido era maximizar a produção e minimizar os salários, protagonizado pelos patrões - que vigiavam cada um dos elementos da massa - e pelo sindicato - o qual mobilizava uma massa de resistência - , em eterna tensão; ao contrário, na empresa - uma alma, um gás, modelo da sociedade de controle tipificado pela captura da participação - há um grande esforço para impor uma modulação para cada salário, a partir de um sistema de recompensa por desempenho, em um estado de perpétua metaestabilidade, no qual se está imerso, continuamente, em uma rivalidade incontornável, marcada pela contraposição dos indivíduos entre $\mathrm{si}^{11}$. Ademais, se o espaço da fábrica era definido, na empresa não há qualquer definição: a atividade é exercida em todos os lugares: no escritório, em casa, na rua e outros. Trata-se da lógica do mercado, tão familiar a um sujeito do século XXI.

A nova faceta é clara: o molde (família, escola, caserna, fábrica, hospital, prisão) é substituído pela modulação (a empresa, o mercado), uma molda- 
gem auto-deformante quemuda a cada instante. 0 princípio modulador se objetifica em controlatos (por exemplo o salário por mérito), o qual, de forma complexa, se imbrica em uma geometria variável, imagética e virtual, como formulada por Virilio ${ }^{33}$. Ademais, se os pólos identificados por Foucault - par indivíduo-massa - são a tônica das sociedades disciplinares, no controleo queimporta é a cifra, uma senha, a qual marca o acesso à informação ou à rejeição (como na citação prévia de Foucault), tornando os indivíduos dividuais e a massa, mera amostra. A passagem se torna explícita, também, no caso do dinheiro: das moedas cunhadas em ouro (limitadas tempo-espacialmente), medida-padrão da disciplina, para câmbios flutuantes, transações de mercado ${ }^{11}$. Desvia-se da toupeira monetária para a serpentefinanceira, em uma passagem que não se faz por escoamento - ao contrário, éturbilhonada - mas queéplenamente perceptível: 0 controle não é uma disciplina. Com uma estrada não seenclausuram pessoas, mas, ao fazer estradas, multiplicam-seosmeiosde controle. Não digo queesseseja o único objetivo das estradas, masas pessoas podem trafegar até 0 infinito e "livremente", sem a mínima clausura, e serem perfeitamente controladas. Esse é o nosso futuro'11.

Tal é o futuro que, tornando-se passado, já se faz plenamente presente, especialmentenos âmbitos da saúde e da educação, como também discutido por Deleuze: Por exemplo, na crise do hospital como meio de confinamento, a setorização, os hospitais-dia, 0 atendimento a domicílio puderam marcar de início novas liberdades, mas também passaram a integrar mecanismos de controle que rivalizam com os mais duros confinamentos ${ }^{11}$.

$N$ o regime das escolas: as formas de controlecontínuo, avaliação contínua, ea ação da formação permanente sobre a escola, 0 abandono correspondente de qualquer pesquisa na U niversidade, a introdução da "empresa' em todos os níveis de escolaridade"1.

Q uais seriam as implicações deste debate para a compreensão do significado da ABP? Seria esta modalidade de estruturação curricular uma das muitas faces do controle?

\section{Educação, saúde e sociedade de controle: a ABP é um controlato?}

Os processos educacionais, nas sociedades de controle, adquirem a mesma fluidez da empresa: "Assim como a empresa substitui a fábrica, a formação permanente tende a substituir a escola, e o controle contínuo substitui o exame $\mathrm{e}^{11 "}$ [grifo do original].

A educação permanente é tema corrente nos discursos oficiais e nas falas cotidianas dos educadores da área de saúde. Em última análise, a crítica insistente aos mecanismos disciplinares na escola médica tem se associado ao exercício ondulante das forças de controle. Por exemplo, a importância da formação profissional em saúde nos dias atuais convive com o enfraquecimento das frontei ras das instituições de ensino ${ }^{34}$, as quais deixam de ser espaços de confinamento - os muros da universidade não definem mais o espaço no qual se estuda: estuda-se em todo lugar e em todo tempo disponível, em uma nítida ocupação das coordenadas espaço-temporais ${ }^{35,36}$; este é o caso da proposta, cada vez mais recorrente, de uma [necessária] integração ensino-serviço. Com efeito, as diferentes propostas de educação permanente (também de educação à distância), especialmente aquela descrita anteriormente, envolvendo todos os atores - alunos, médicos, profissionais de saúde em geral, profissionais administrativos, pacientes e familiares ${ }^{29}$, caracterizando um certo tipo de porosidade ao entorno - evidenciam a expansão das interven ções educacionais para além dos limites da universidade. Um dos objetivos amplos deste processo éformar o cidadão integral, a partir da participação/intervenção/controle de todos os envolvidos, os quais assumem do papel de educadores, atuando/interferindo nos diferentes aspectos das respectivas formações.

É neste contexto que ganha importância a avaliação formativa, ininterrupta, capaz de olhar o processo nos vários espaços sem limites de ensino-aprendizagem - na universidade e fora dela — , um dos mais efetivos métodos para o controle. O bservar, de perto, o progresso dos aprendizes de médico, podendo interferir de forma mais ou menos recorrente - "olhe, você precisa mel horar, seu desempenho está aquém do esperado" - está inscrito nesta lógica. As notas, formalização da disciplina, são substituídas pelo conceito fluido de suficiência; se antes era possível receber uma nota para, então, passar de uma série a outra, agora é dado um grau suficiente ou insuficiente, para manter (indefinidamente) o processo de formação. A "formatura" em medicina passa a significar, outrossim, não o término do curso de fato, mas o início de um processo de educação permanente que não cessa de transcorrer, ou seja: [...] nas sociedades de controle nunca se termina nada, a empresa, a formação, o serviço sendo os estados metaestáveis e coexistentes de uma mesma modulação, como que um deformador universal ${ }^{11}$.

As consequências disto não se fazem tardar: ampliam-seasfileiras constituídas por eternos estudantes, para os quaiso conhecimento - agora sinô- 
nimo de informação - torna-se rapidamente ultrapassado, tornando imperiosa a aquisição, infrene, de novas informações, as quais são a resposta ao status quo de competitividade exigida pelo mercado. A atualização deixa, assim, de ser pressuposto para uma boa prática, passando a ser, nas palavras de Chevitarese, quase uma obsessão cultural ${ }^{36}$.

Estes novos processos de controle têm profundas implicações na (in)formação do profissional de saúde e, por consequência, na sua prática. De fato, a ideologia dominante na saúde - eficazmente incorporada ao discurso oficial - se concretiza em novos contornos. O s hospitais - célebres espaços de confinamento, como bem demonstrado em toda a atitude policial esca da psiquiatria no último século - deram lugar à medicina sem médico nem doente ${ }^{11}$; a ascensão da saúde pública/coletiva - como nos debates sobre promoção à saúde - torna todos os sujeitos doentes em potencial, para os quais o adiamento da enfermidade tem como preço a constante vigilância - à saúde! - , a régia observância às orientações dos profissionais de saúde. Este é, precisamente, o caso dos sintomáticos respiratórios (pessoas que tossem há mais do que três semanas), potenciais tuberculosos, os quais deverão ser identificados nas comunidades, rastreados para a infecção pelo M ycobacterium tuberculosis (através da baciloscopia de escarro) e tratados, impedindo-se, assim, a disseminação do mal ${ }^{37}$.

Ainda sobre a saúde, cabe o comentário acerca do desenvolvimento da biotecnociência. A colonização da vida nua, a qual se concretiza cada vez mais na possibilidade da manipulação genética, tem explicitado os riscos aos quais se pode estar sujeito, em decorrência de uma má herança genética. Podem ser mencionados os testes para detecção do risco de câncer de mama, o qual, uma vez identificado, deverá motivar um controle permanente para o diagnóstico e tratamento do mal. Como no filme Gattaca, todos podem ser virtualmente" portadores" de condições mórbidas diversas, cabendo, assim, a necessidade de desenvolver tecnologias capazes de identificar e extirpar os maus genes, quiçá no momento - ou antes mesmo - da concepção. Como nas palavras de Renato M anfredini Júnior, o Renato Russo, "nos deram espelhos e vimos um mundo doente" 38 .

Com base em todo este panorama, torna-se defensável a idéia de que a ABP está inscrita nesse emergente ordenamento - o controle - , especialmente ao perscrutarem-se os elementos concernentes à educação permanente e à avaliação. Com efeito, na medida em que a ABP pretende formar profissionais mais capazes de responder às neces- sidades de saúde da população, e que tais necessidades estão cada vez mais inscritas na nova ordem mundial tipificada nas sociedades de controle, a conclusão - resposta à indagação que motivou tal trabalho - , não se faz tardar: a ABP pode ser caracterizada como um controlato, ao menos da maneira segundo a qual vem sendo pensada e executada na atualidade.

\section{Consideraçõesfinais: \\ transformação eresistência}

Uma visão superficial e precipitada da discussão entabulada atéo presentemomento podefazer pensar que, indiretamente, se tenha estabelecido uma defesa - como consequência da crítica à aprendizagem baseada em problemas - , do mantenimento da educação médica nos moldes ditos tradicionais, o sistema disciplinar. Ledo engano. É ingênuo pensar desta maneira, precisamente por não ser possível dizer qual éo melhor regime - a sociedade disciplinar ou a sociedade de controle - , na medida em que cada um deles tem suas especificidades - mormenteno estabel ecimento edesempenho dos mecanismos, terríveis e obscuros, de exercício do poder - , como discutido pelo próprio Deleuze: Não se deve perguntar qual é o regime mais duro, ou 0 mais tolerável, poiséem cada um deles que se enfrentam as liberações e as sujeições. [ ...] Não cabe temer ou esperar, mas buscar novas armas ${ }^{11}$.

As respostas não são fáceis, de modo que buscá-las, movido por um espírito simplificador, configura-seinocência. A necessidade detransformar a educação profissional em saúde - formação mé dica incluída - éuma constatação quedificilmente pode ser contestada, como vem sendo amplamente discutido na literatura especial izada ${ }^{1,39}$ - afinal, não cabem mais os confinamentos disciplinares de anatomia, bioquímica, cirurgia e outros, e, tampouco, a passagem por espaços "fechados" dentro do próprio curso, como no caso do básico ao clínico ${ }^{40}$. Por outro lado, o controle já é uma realidade, bastando-se olhar para o quanto os indivíduos dividuais vêm sendo rastreados no momento atual, em coisas do tipo: "sorria, você está sendo filmado"; ou "resolveremos o problema da segurança (pública) instalando circuitos de TV nos diferentes espaços (públicos)"; ou "as quebras de sigilo fiscal e tel efônico ajudaram nas investigações"; esta éigualmente a lógica do desenvolvimento dos sistemas de busca na internet; ou, ainda, na espiada em um simples e "inofensivo" programa como o Big Brother...

Como compor tal situação?

É preciso pensar. Estes momentos aporéticos - 
i.e., de beco sem saída - são aqueles nos quais sefaz mais necessário colocar o pensamento em ação, rejeitando o [que parece] óbvio ebuscando novas orientaç̃̃es para a ação. Em última análise, se a ABP "nasceu" como uma forma de resistência ao carcomido currículo disciplinar na escola médica, colocando-se na vanguarda por permitir uma reflexão/ ação acerca do saber-fazer em saúde - o qual pode ser compreendido como solvência de problemas , é possível conformar modos para permanecer na resistência ao controle no âmago da aprendizagem baseada em problemas. Resistir a transformar a ava- liação em exercício de captura... Resistir a conceber a educação permanente como negação da terminalidade, que oculta, de fato, uma perspectiva de condução dividual dos profissionais de saúde, em termos da lógica demercado. Para isto émister seatrever a pensar, exercer a coragem para questionar, mesmo queao final sevislumbre, como único caminho, a própria transformação [radical] da ABP.

Se "os anéis de uma serpente são ainda mais complicados que os buracos de uma toupeira ${ }^{11 "}$, fica o convite: pensar, uma vez que, definitivamente, não cabe temer ou esperar...

\section{Colaboradores}

R Siqueira-Batista concebeu o presenteartigo, tendo formulado sua estruturação originária; R Siqueira-Batista participou como um leitor crítico do manuscrito, contribuindo, decisivamente, para o debate sobre as sociedades de controle.

\section{Referências}

1. Ceccim RB, Feuerwerker LCM. M udança na graduação das profissões de saúde sob o eixo da integralidade. Cad. Saude Publica 2004; 20(5):1400-1410.

2. Feuerwerker L. Além do discurso de mudança na educação médica: processos e resultados. São Paulo: Hucitec; Londrina: Rede Unida; Rio de Janeiro: Associação Brasileira de Educação M édica, 2002. M itre SM,

3. Siqueira-Batista R, Girardi-de-M endonça JM, M oraisPinto NM, M eirelles CAB, Pinto-Porto C, M oreira T, Hoffmann LMA. M etodologias ativas de ensino-aprendizagem na formação profissional em saúde: debates atuais. Cien Saude Colet 2008; 13(6):2133-2144.

4. Venturelli J. Educación médica: nuevos enfoques, metas y métodos. 2a ed. Washington, D.C.: Organización Panamericana de la Salud/Organización Mundial de la Salud; 2003.

5. M oraes M AA, M anzini EJ. Concepções sobre a aprendizagem baseada em problemas: um estudo de caso na Famema. Rev Bras Educ M ed 2006; 30(3):125-135.

6. Prigogine I. 0 fim das certezas. São Paulo: Unesp; 1996.

7. Motta LB, Aguiar AC. Novas competências profissionais em saúde e o envelhecimento populacional brasileiro: integralidade, interdisciplinaridade e intersetorialidade. Cien Saude Colet 2007; 12(2):363-372.

8. Alves VS. Um modelo de educação em saúde para o Programa Saúde da Família: pela integralidade da atenção e reorientação do modelo assistencial. Interface - Comunic., Saúde, Educ. 2005; 9(16):39-52.

9. Schramm FR. Bioética para quê? Revista Camiliana da Saúde 2002; 1(2):14-21.

10. Baudrillard J. A sociedade de consumo. Lisboa: Edições 70; 1981. 
11. Deleuze G. Post-scriptum sobre as sociedades de controle. In: Deleuze G. Conversações: 1972-1990. Rio de Janeiro: Editora 34; 1992.

12. Lima VV, Komatsu R, Padilha RQ. Uni-marília: capacitação de recursos humanos e desenvolvimento de lideranças. Divulg Saúde Debate 1996; 12:90-96.

13. Almeida MJ. Educação médica e saúde: possibilidades de mudança. Londrina: Ed. UEL; Rio de Janeiro: ABEM ; 1999.

14. Fundação Educacional Serra dos Órgãos. Projeto de mudança curricular no Curso de Graduação em M edicina. Teresópolis: FESO; 2002.[M imeo]

15. Dewey J. Democracia e educação. 3a. ed. São Paulo Nacional; 1959.

16. Dewey J. Liberalismo, liberdade e cultura. São Paulo: Nacional; 1970.

17. Fiúza M oreira CA. Entre o indivíduo e a sociedade: um estudo da filosofia da educação de John D ewey. Bragança Paulista: EDUSF; 2002.

18. Piaget J. A equilibração das estruturas cognitivas. Rio de Janeiro: Zahar; 1976.

19. Vigotsky LS. A formação social da mente: 0 desenvolvimento dos processos psicológicos superiores. 6a ed. São Paulo: $M$ artins Fontes; 1998.

20. Freire P. Pedagogia da autonomia. Saberes necessários à prática educativa. São Paulo: Paz e Terra; 2003.

21. Freire P. Pedagogia do oprimido. $38^{a}$ ed. São Paulo: Paz e Terra; 2004.

22. Ausubel D, Novak JD, Hanesian H. Educational Psychology, a Cognitive View. New York: Holt, Reinhart and Wiston; 1978.

23. Gomes AP, Dias Coelho UC, Cavalheiro PO, Gonçalvez CAN, Rôças G, Siqueira-Batista R. A educação médica entre mapas e âncoras: a aprendizagem significativa de David Ausubel, em busca da arca perdida. Rev Bras Edu M éd 2008; 32(1):105-111.

24. Schramm FM. A autonomia difícil. Bioética 1998 $6(1): 27-37$

25. Costa CRBSF, Siqueira-Batista R. As teorias do desenvolvimento moral e o encino médico: uma reflexão pedagógica centrada na autonomia do educando. Revista Brasileira de Educação M édica 2004; 28(3):242-250

26. Fundação Educacional Serra dos Órgãos. M anual para tutores e instrutores do primeiro período. Teresópolis: FESO; 2006.

27. Cyrino EG, Toralles-Pereira ML. Trabalhando com estratégias de ensino-aprendizado por descoberta na área da saúde: a problematização e a aprendizagem baseada em problemas. Cad. Saude Publica 2004; 20(3):780-788.
28. Siqueira-Batista R. Aprendizagem baseada em problemas: uma estratégia das sociedades de controle [trabaIho de conclusão de curso]. Rio de Janeiro (RJ): Fundação Oswaldo Cruz; 2006.

29. De M arco MA. Do modelo biomédico ao modelo biopsicossocial: um projeto de educação permanente. Rev Bras Edu M éd 2006; 30(1):60-72.

30. Foucault M. Ditos e escritos IV: estratégia, poder-saber. Rio de Janeiro: Forense Universitária; 2003.

31. Foucault M. A vontade do saber. Rio de Janeiro: Graal; 1977.

32. Kafka F. 0 processo. São Paulo: Companhia das Letras; 2005.

33. Virilio P. 0 espaço crítico. Rio de Janeiro: Editora 34; 1993.

34. Martins AM . A política do conhecimento: a identidade do saber e as reformas educativas. In: Linhares C. Políticas do conhecimento. Velhos contos, novas contas. Niterói: Intertexto; 1999. p. 71-100.

35. Chevitarese LP, Pedro RMLR. Da sociedade disciplinar à sociedade de controle: a questão da liberdade por uma alegoria de Franz Kafka, em 0 Processo, e de Phillip Dick, em M inority Report. Estudos de sociologia (UFPE) 2005; 8(1):129-162.

36. Chevitarese LP. A questão da "liberdade" na sociedade de controle, por uma alegoria de Kafka em 0 processo. Análogos 2004; 4:44-60.

37. Brasil. M inistério da Saúde. Secretaria de Políticas de Saúde. Departamento de Atenção Básica. M anual Técnico para o controle da tuberculose: cadernos de atenção básica. 6a ed. Brasília: Ministério da Saúde; 2002.

38. Legião Urbana. Dois [disco]. São Paulo: Emi Odeon; 1986.

39. Marins JJN, Rego S, Lampert JB, Araújo JGC. Educação médica em transformação: instrumentos para a construção de novas realidades. São Paulo: Hucitec/ABEM ; 2004.

40. Santos SS. A integração do ciclo básico com o profissional no Curso de Graduação em M edicina: uma resistência exemplar. Rio de Janeiro: Papel \& Virtual; Teresópolis: FESO, 2005.

Artigo apresentado em 01/11/2006

Aprovado em 15/12/2006

Versão final apresentada em 30/07/2007 